\title{
Composition dependent thermal annealing behaviour of ion tracks in apatite
}

\author{
A. Nadzri ${ }^{\mathrm{a}, *}$, D. Schauries ${ }^{\mathrm{a}}$, P. Mota-Santiago ${ }^{\mathrm{a}}$, S. Muradoglua ${ }^{\mathrm{a}}$, C. Trautmann ${ }^{\mathrm{b}, \mathrm{c}}$, \\ A.J.W. Gleadow ${ }^{\mathrm{d}}$, A. Hawley ${ }^{\mathrm{e}}$, P. Kluth ${ }^{\mathrm{a}}$ \\ aDepartment of Electronic Materials Engineering, Research School of Physics and Engineering, Australian \\ National University, Canberra, ACT 2601, Australia

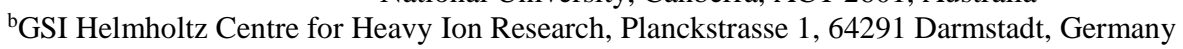 \\ 'Technische Universität Darmstadt, 64287 Darmstadt, Germany \\ dSchool of Earth Science, University of Melbourne, Melbourne VIC 3010, Australia \\ eAustralian Synchrotron, 800 Blackburn Road, Clayton, VIC 3168, Australia
}

\begin{abstract}
Natural apatite samples with different $\mathrm{F} / \mathrm{Cl}$ content from a variety of geological locations (Durango, Mexico; Mud Tank, Australia; and Snarum, Norway) were irradiated with swift heavy ions to simulate fission tracks. The annealing kinetics of the resulting ion tracks was investigated using synchrotron-based small-angle x-ray scattering (SAXS) combined with ex situ annealing. The activation energies for track recrystallization were extracted and consistent with previous studies using track-etching, tracks in the chlorine-rich Snarum apatite are more resistant to annealing than in the other compositions.
\end{abstract}

Keywords: Apatite, latent ion track, thermal annealing, SAXS

* Corresponding author. Tel.: +61 2612 50868; e-mail: allina.nadzri@anu.edu.au

\section{Introduction}

Minerals such as apatite often contain trace amounts of radioactive ${ }^{238} \mathrm{U}$. Spontaneous fission of these $U$ impurities can produce two highly charged fission fragments [1]. The radioactive decay releases energies around $170 \mathrm{MeV}$ that is split between a heavy and a light fragment of about 100 and $70 \mathrm{MeV}$, respectively [2,3] . Due to the high energy of the fragments they penetrate the crystalline material interacting with it predominantly through inelastic interactions with the material electronic system [1,3]. Coupling of this energy into the atomic system leads to the formation of amorphous cylinder-like damage trails the so-called 'fission track'. These tracks are typically a few nanometres wide and about $10 \mu \mathrm{m}$ long. Upon exposure to elevated temperatures, these tracks are known to shrink in size as a consequence of the gradual recovery of the crystalline structure $[4,5]$.

Fission tracks are used to determine the age of archaeological and geological samples as well as their thermal history by studying the number and length distribution of chemically etched tracks $[3,6]$. The specific chemical etchant used preferentially attacks the damaged region, enlarging the track diameter to allow imaging them by optical microscopy. Etching however removes the material inside the ion tracks as well as inside other local damaged zones that may exist in the mineral, erasing all information about the primary track damage and its dependence on the geological and material parameters [1].

In this work, tracks of comparable diameter were created by irradiation with swift heavy ions to simulate fission track damage. Controlled irradiation leads to the formation of parallel identical tracks. This enables accurate characterisation of the 'latent' un-etched tracks by synchrotron-based small angle x-ray scattering (SAXS). We have previously demonstrated that 
SAXS is a powerful, non-intrusive method to analyse the morphology and annealing behaviour of un-etched ion tracks [4, 5, 7-9].

Studies using chemical etching show that the annealing behaviour of fission tracks in apatite is dependent on the halide ratio and apatites richer in fluorine annealed faster than those richer in chlorine [10-14]. We now investigate the effects of thermal annealing on latent tracks in apatite from different geological locations with different halide composition. We study the reduction in track radii upon partial annealing of the ion tracks. This is an important step for determining the correlation between the primary damage in the mineral and relevant geological parameters.

\section{Experimental techniques}

\subsection{Sample preparation and irradiation}

This study was carried out using natural apatite samples from three different regions with different halogen composition. Apatite is a mineral group with the chemical formula of $\mathrm{Ca}_{5}\left(\mathrm{PO}_{4}\right)_{3} \mathrm{X}$ with $\mathrm{X}$ representing the halide composition such as $\mathrm{F}$ (fluorapatite), $\mathrm{OH}$ (hydroxyapatite) or $\mathrm{Cl}$ (chlorapatite) [15]. Apatite is anisotropic, with an hexagonal lattice structure of $P 6_{3} / m$ [16]. Table 1 lists the locality and the $\mathrm{Cl}$ and $\mathrm{F}$ contents for the three apatite samples used in this study, based on electron microprobe and wet chemical analyses.

Table 1: Geographical origin and halide composition of the studied apatite samples.

\begin{tabular}{cccc}
\hline Apatite name & Locality & $\mathrm{F}(\mathrm{wt} \%)$ & $\mathrm{Cl}(\mathrm{wt} \%)$ \\
\hline Durango & Durango, Mexico & $3.40-3.53[17,18]$ & 0.43 \\
Mud Tank & $\begin{array}{c}\text { Mud Tank Mine, } \\
\text { NT, Australia }\end{array}$ & 2.93 & 0.040 \\
Snarum & Snarum, Norway & 1.01 & 2.49 \\
\hline
\end{tabular}

The samples were pre-annealed at $450^{\circ} \mathrm{C}$ for 24 hours to remove all natural tracks present in the apatite crystals. Thin slices of the crystal were then prepared by cutting and polishing to thickness between $80-120 \mu \mathrm{m}$ to minimise x-ray absorption during the SAXS measurements. Subsequently, samples were irradiated at the UNILAC accelerator at the GSI Helmholtz Centre in Darmstadt, Germany using 2.3 GeV Bi ions at room temperature. Samples were irradiated with the ion beam normal to the polished surface.

As estimated by SRIM-2010 [19], the projected ion range is roughly $78 \mu \mathrm{m}$ and the electronic energy loss $d E / d x$ on the sample surface is $29.1 \mathrm{keV} / \mathrm{nm}$ for apatite, independent of halide composition. This value is of comparable magnitude as natural fission fragments (100 $\mathrm{MeV}$ ) where the $d E / d x$ is approximately $15 \mathrm{keV} / \mathrm{nm}$. In order to minimise track overlap, an irradiation fluence of $1 \times 10^{11}$ ions $/ \mathrm{cm}^{2}$ was used. For this value, less than $5 \%$ of the surface is covered with ion tracks with negligible overlap [8].

\subsection{SAXS measurement}

For characterization of the ion tracks, transmission SAXS measurements were performed at the SAXS/WAXS beamline at the Australian Synchrotron in Melbourne, Australia. The experiments were carried out with an x-ray energy of $11 \mathrm{keV}$ and a sample- 
detector distance of approximately $1.6 \mathrm{~m}$. Measurements were taken with exposure times of 1 , 2, 5 and 10 seconds, producing images with sufficient intensity for accurate data analysis. Different exposure times were used to ensure that measurements were well within the linear regime of the detector. The tracks were tilted by $10^{\circ}$ with respect to the $\mathrm{x}$-ray beam using a three-axis goniometer.

To study the recovery kinetics of the ion tracks in apatite, ex situ annealing was performed in a conventional furnace under ambient atmosphere. Samples were annealed at temperatures between 200 and $410^{\circ} \mathrm{C}$ with an initial increment of $50^{\circ} \mathrm{C}$ that was later reduced to $20^{\circ} \mathrm{C}$ to better resolve reductions in track radii near the closure temperature. Samples were annealed for 30 minutes at each temperature and SAXS measurements were recorded between annealing steps at room temperature. An unirradiated sample was measured for background removal.

\section{Results and discussion}

Figure 1 shows selected SAXS detector images for the three apatite samples before and after annealing at $310^{\circ} \mathrm{C}$ and $390{ }^{\circ} \mathrm{C}$. Before annealing, all samples display a strong scattering signal from the tracks concentrated in the oscillating narrow bent streaks. These streaks result from the high aspect ratio of the aligned, tilted ion tracks and contain information about their radial density $[3,4,8]$. At $390^{\circ} \mathrm{C}$ the scattering signal from the tracks is significantly reduced in intensity and the oscillations in the streak intensity 'washed out' for all three apatite compositions, indicating a partial recovery of the crystalline structure.

The scattering intensities as a function of the scattering vector $q$ from the SAXS images observed are shown in figure 2 (a-c) for all annealing temperatures. The oscillations in the scattering intensities suggest monodisperse radii and sharp boundaries between the track and matrix material, consistent with amorphous tracks [4]. All compositions display a shift of the first minimum to higher $q$ with increasing annealing temperature. This indicates a reduction in the track radius. At higher temperatures, the oscillations become noticeable washed out for most samples. To best describe the experimental results, a simple cylinder model is used [4]. The model assumes parallel almost identical tracks [5]. A narrow Gaussian distribution of track radii is used to account for deviations from this idealistic model. The fits to this model are represented by the solid lines in figure 2. The width of the Gaussian distribution (polydispersity) is increasing from approximately $5 \%$ of the ion track radius at room temperature to $\sim 10 \%$ at higher temperatures for all apatite compositions. The observed increase in the polydispersity can possibly be related to a softening of the track boundaries due to diffusion processes during recrystallization.

Figure 2 (a) shows the SAXS patterns for ion tracks in Durango apatite. As mentioned before, at room temperature, the sample shows strong scattering from tracks with clear oscillations. Traces of the tracks remain evident for temperatures above $390{ }^{\circ} \mathrm{C}$, however the extraction of useful data becomes difficult due to the low scattering intensity and the absence of oscillations. Similar to Durango apatite, figure 2 (b) and (c) show the SAXS patterns for Mud Tank and Snarum apatite, respectively, for each annealing step. For the latter, slight deviations of the model fits and the data are apparent, that may be caused by deviations from the simple cylindrical model for this apatite composition. While we are currently investigating other suitable models, the relative changes in the track radii are unlikely to be influenced by the model choice. 


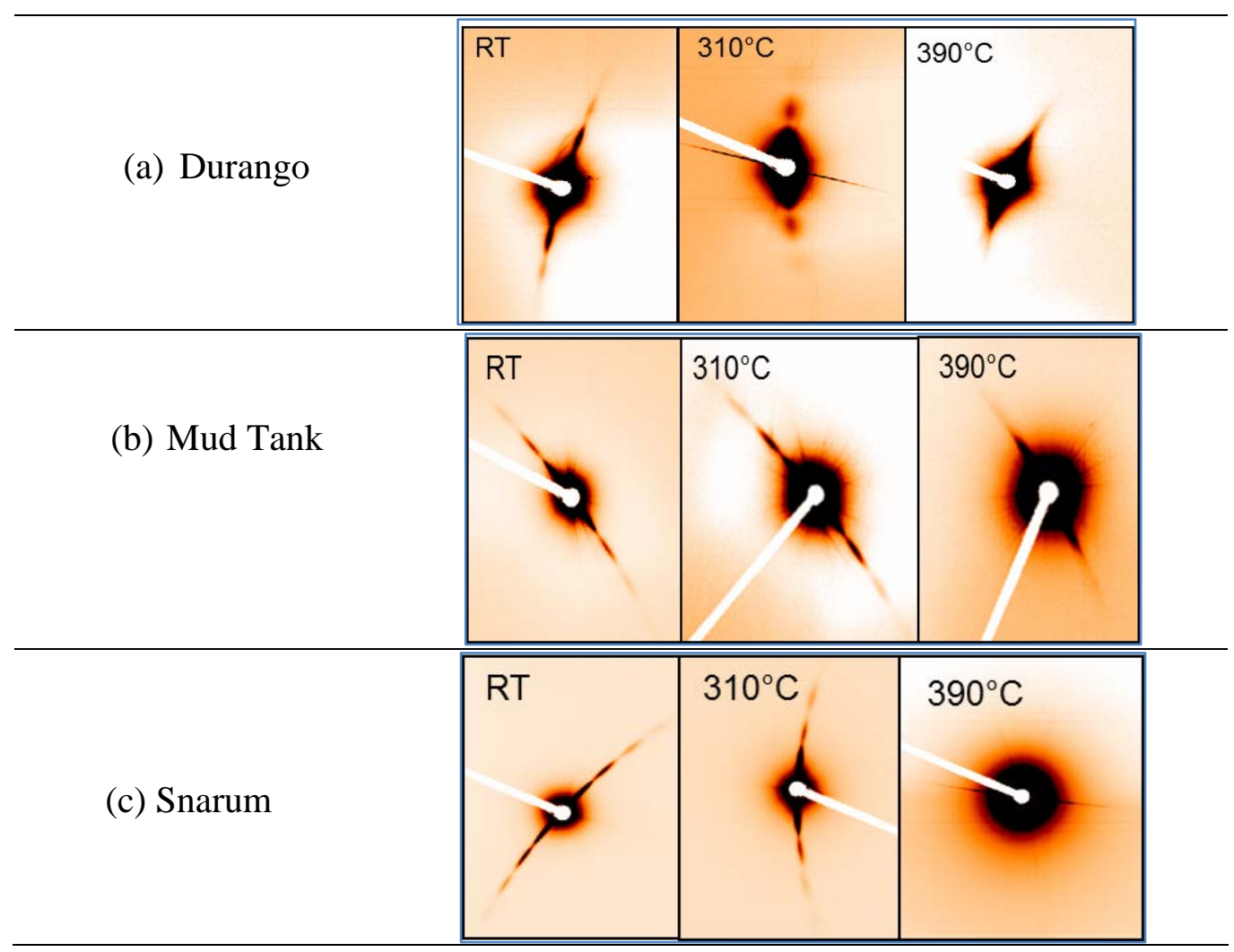

Figure 1. Selected SAXS detector images of ion tracks in apatite from (a) Durango, Mexico (b) Mud Tank, Australia, and (c) Snarum, Norway. The images are shown for tracks before annealing (left column), and after annealing at $310^{\circ} \mathrm{C}$ (middle column) and $390{ }^{\circ} \mathrm{C}$ (right column). 

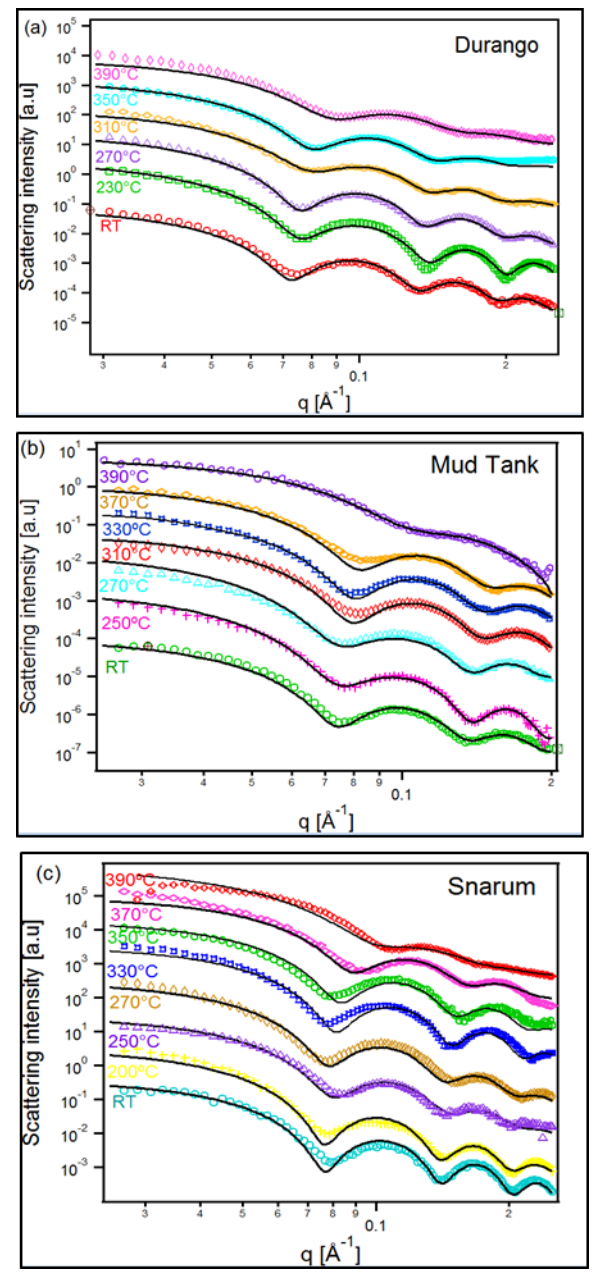

Figure 2. Scattering intensities as a function of scattering vector $q$ for apatite from (a) Durango, (b) Mud Tank and (c) Snarum prior to annealing and after successive annealing at different temperatures for 30 minutes each. (Scattering data is shown as symbols and hard cylinder model fits as solid lines. The intensity for each curve is offset for clarity).

Figure 3 shows the ion track radii as a function of the annealing temperature for all three compositions studied. Durango apatite shows the highest track radius $(5.5 \mathrm{~nm})$ at room temperature followed by Mud Tank $(5.3 \mathrm{~nm})$ and Snarum $(5.1 \mathrm{~nm})$. This observation is an indication that the Cl-rich apatite is more resistant to track formation than the other compositions. At the early stages of annealing, the track radii do not change significantly up to approximately $270{ }^{\circ} \mathrm{C}$, after which they rapidly shrink. In Durango apatite, for example, the value drops by about $1.3 \mathrm{~nm}$ to approximately $4 \mathrm{~nm}$. A similar behavior has been observed for the other two compositions yet the reduction in track radii is lower than that in Durango apatite. This is visualised in the inset to figure 3, where the track radii are plotted normalised to the RT radius. It can be observed that apatite from Snarum shows the slowest annealing rate with a track radius reduction at $390{ }^{\circ} \mathrm{C}$ of only $12 \%$ from the initial value. 


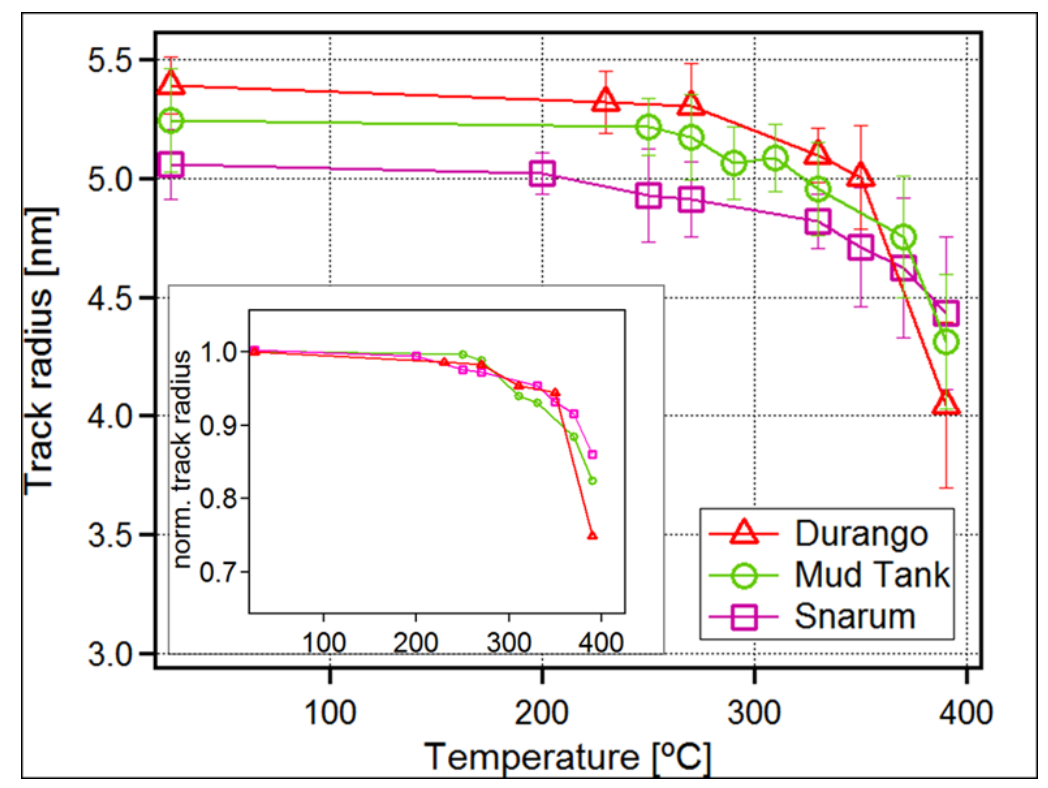

Figure 3. Track radius as a function of annealing temperature for all studied compositions. The inset shows the same data with the track radii normalized to that of the unannealed samples for comparison.

The deduction of the track radius as a function of annealing temperature allows an estimation of the relevant activation energies $E_{\mathrm{A}}$ of the damage recovery using an Arrhenius equation [5, 12]. By taking the natural logarithm of the Arrhenius equation, we obtain:

$$
\ln \left(1-\frac{R}{R_{0}}\right)=\frac{-E_{A}}{k_{b}} \frac{1}{T}+\ln (A)
$$

where $\mathrm{R}$ is the current radius, $\mathrm{R}_{0}$ the initial radius, $\mathrm{k}_{\mathrm{b}}$ the Boltzmann constant, $\mathrm{T}$ the annealing temperature in Kelvin and A a dimensionless constant.

Figure 4 (a-c) show the Arrhenius plots using the data obtained from the ex situ annealing experiments of three apatite compositions (see figure 3). The plots suggest two different stages of annealing for all compositions at low and high temperatures with different values $E_{A}$ consistent with previous studies on Durango apatite [4]. The linear fits in figure 4 yield the activation energies of the two stages. Stage I (dashed lines) represents annealing at temperatures below $300{ }^{\circ} \mathrm{C}$ while stage II (solid lines) are the data points for annealing temperature above $300{ }^{\circ} \mathrm{C}$. Stage II shows a more rapid decrease of the track radius characterized by the higher activation energy and in agreement with recrystallization of the amorphous material in the ion track [5]. The activation energies are $0.13 \pm 0.00 \mathrm{eV}$ for stage I and $0.90 \pm 0.12 \mathrm{eV}$ for stage II for Durango apatite, $0.22 \pm 0.02 \mathrm{eV}$ for stage I and $0.67 \pm 0.06$ $\mathrm{eV}$ for stage II for Mud Tank apatite, and $0.17 \pm 0.03 \mathrm{eV}$ for stage I and $0.44 \pm 0.07 \mathrm{eV}$ for stage II for Snarum apatite.

As recrystallization occurs in the higher temperature range, we focus in the discussion on stage II of the recrystallization. Earlier we have obtained an activation energy of $0.72 \pm 0.02$ $\mathrm{eV}$ for Durango apatite using similar experimental techniques [5]. The value obtained in this study agrees somewhat with earlier value. A possible explanation for the observed difference could include differences in the crystallographic direction of the ion tracks or natural variations in the composition. Given this variation, the slightly lower activation energy observed for stage II in Mud Tank compared to Durango apatite may be related to such a fluctuation and as such 
we refrain from over-interpreting this difference. However, it may be related to the change in $\mathrm{F} / \mathrm{Cl}$ ratio. Snarum apatite, on the other hand, exhibits stage II activation energy of $0.44 \pm 0.07$ $\mathrm{eV}$, significantly lower than those for the other two compositions. The main difference in the composition of Snarum apatite is the much higher $\mathrm{Cl}$ content. As reported by Barbarand et al [10], chlorine has a significant influence on the apatite structure above 0.1 anion per formula unit ( 0.35 wt. \%). Increased chlorine substitution is reflected by an increase in cell lattice a and decrease in lattice c parameters of

the hexagonal unit cell. Green et al [13] have previously shown that tracks with higher $\mathrm{Cl}$ content are more resistant to annealing and that F-rich apatite are less resistant thus record cooler temperatures.

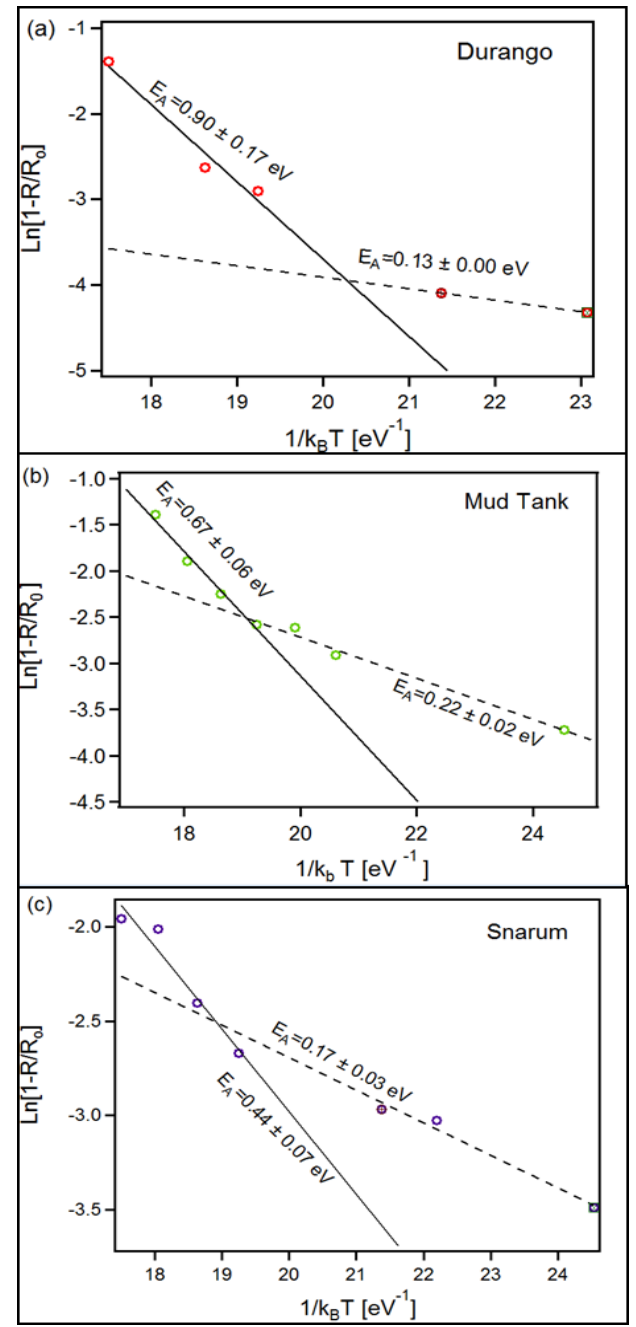

Figure 4. Arrhenius plot of the ion track radii vs reciprocal temperature for apatite from (a) Durango, (b) Mud Tank and (c) Snarum. The solid lines display a linear fit for annealing at temperatures $\geq 300{ }^{\circ} \mathrm{C}$ (Stage II) and the dashed line corresponds to data from annealing at temperature $\leq 300^{\circ} \mathrm{C}$ (Stage I).

While all previous studies of the composition dependent annealing behaviour used etched ion tracks, these results clearly show that the variations in fluorine and chlorine composition in apatite are already impacting the un-etched fission track size and annealing properties, that later translate to differences in etched tracks that are used for the current dating techniques. This supports previous finding where Cl-rich apatite showed slower annealing than F-rich apatites [10, 12, 13]. 


\section{Conclusions}

We have investigated the annealing kinetics of latent ion tracks in apatite of different halide composition (fluor- and chlor-) by combining synchrotron based SAXS with ex situ annealing. Analysis of the SAXS data showed a smaller initial track radius and a higher resistance to annealing in the Cl-rich Snarum apatite. Two stages of track recovery were identified and the activation energies estimated from the annealing experiments. Above $300^{\circ} \mathrm{C}$, the activation energies for track recrystallization were deduced to be $0.90 \pm 0.12 \mathrm{eV}, 0.67 \pm 0.06 \mathrm{eV}$ and 0.44 $\pm 0.06 \mathrm{eV}$ for ion tracks in apatite from Durango, Mud Tank and Snarum, respectively. With the small amount of reduction, we conclude that this is only partial track annealing. The study also confirms the importance of the halide composition for the recovery of track damage that was earlier seen in etched fission tracks.

\section{Acknowledgements}

This research was undertaken on the SAXS/WAXS beamline at the Australian Synchrotron. P.K. acknowledges the Australian Research Council for financial support. A.N would like to acknowledge the Universiti Teknologi Mara (Malaysia) and Ministry of Higher Education, Malaysia for financial support. 


\section{References}

1. R.L. Fleischer, P.B. Price and R.M. Walker. Series Nuclear tracks in solids: principles and applications. 1975: Univ of California Press.

2. $\quad$ R.L. Fleischer, Journal of Materials Science, 2004. 39: 3901.

3. G.A. Wagner and P. Van den Haute. Series Fission Track Dating. 1992, Kluwer Academic Publishers: Dordrecht.

4. $\quad$ B. Afra, M. Lang, T. Bierschenk, M.D. Rodriguez, W.J. Weber, C. Trautmann, R.C. Ewing, N. Kirby and P. Kluth, Nucl. Instr. Meth. Phys. Res. B, 2014. 326: 126.

5. B. Afra, M. Lang, M.D. Rodriguez, J. Zhang, R. Giulian, N. Kirby, R.C. Ewing, C. Trautmann, M. Toulemonde and P. Kluth, Phys. Rev. B, 2011. 83: 064116.

6. A.J. Gleadow, D.X. Belton, B.P. Kohn and R.W. Brown, Reviews in Mineralogy and Geochemistry, 2002. 48: 579.

7. P. Kluth, C. Schnohr, D. Sprouster, A. Byrne, D. Cookson and M. Ridgway, Nucl. Instr. Meth. Phys. Res. B, 2008. 266: 2994.

8. D. Schauries, M. Lang, O. Pakarinen, S. Botis, B. Afra, M. Rodriguez, F. Djurabekova, K. Nordlund, D. Severin and M. Bender, J. Appl. Cryst. , 2013. 46: 1558

9. D. Schauries, M. Rodriguez, B. Afra, T. Bierschenk, C. Trautmann, S. Mudie and P. Kluth, Nucl. Instr. Meth. Phys. Res. B, 2015.

10. J. Barbarand, A. Carter, I. Wood and T. Hurford, Chemical Geology, 2003. 198: 107.

11. W.D. Carlson, R.A. Donelick and R.A. Ketcham, American Mineralogist, 1999. 84: 1213.

12. P. Green, I. Duddy, A. Gleadow, P. Tingate and G. Laslett, Nuclear Tracks and Radiation Measurements 1985. 10: 323.

13. P. Green, I. Duddy, A. Gleadow, P. Tingate and G. Laslett, Chemical Geology: Isotope Geoscience section, 1986. 59: 237.

14. P.B. O'Sullivan and R.R. Parrish, Earth and Planetary Science Letters, 1995. 132(1): 213.

15. J.C. Elliott. Series Structure and chemistry of the apatites and other calcium orthophosphates. 2013: Elsevier.

16. P. Wu, Y.Z. Zeng and C.M. Wang, Biomaterials, 2004. 25: 1123.

17. B. Goldoff, J.D. Webster and D.E. Harlov, American Mineralogist, 2012. 97(7): 11031115.

18. E.J. Young, A.T. Myers, W.L. Munson and N.M. Conklin, U.S. Geological Survey of Professional Paper, 1969(650D): D84-D93.

19. J.F. Ziegler, M.D. Ziegler and J.P. Biersack, Nucl. Instr. Meth. Phys. Res. B, 2010. 268: 1818. 